\title{
History of radar: the need for further analysis and disclosure
}

\author{
Gaspare Galati \\ Tor Vergata University \\ Department of Electronic Engineering \\ and "Vito Volterra" Centre \\ Via del Politecnico, 1 - 00133 Rome, Italy \\ e-mail: gaspare.galati@uniroma2.it
}

\author{
Piet van Genderen \\ Delft University of Technology \\ Department of Electrical Engineering, \\ Mathematics and Computer Science \\ Mekelweg 4 - PO Box 5031-2600 GA Delft, Netherlands \\ e-mail: P.vanGenderen@tudelft.nl
}

\begin{abstract}
Within the frame of the Eurad-2014 Special Session «110 years of radar developments in Europe after Hülsmeyer's Telemobiloskop» this introductory paper contains (i) a retrospective analysis of the present literature and of its missing elements and (ii) a kind of presentation of this Special Session and its rationale.
\end{abstract}

\section{Keywords: Radar, History, Telemobiloskop, Hülsmeyer, Digital} Radar, Ukraine.

\section{INTRODUCTION - THE BEGINNING}

The history of radar development has been publicly discussed at least at three occasions (and in three different towns: Eydelstedt, Warsaw and Toulouse) in 2004, one hundred years after the "rediscovered" Hülsmeyer patent on the Telemobiloskop, [1], [2]. Moreover, an earlier historical conference was held in London in 1985, i.e. fifty years after the development of the first operational radars) [3], [4]. See Figures 1 and 2 .

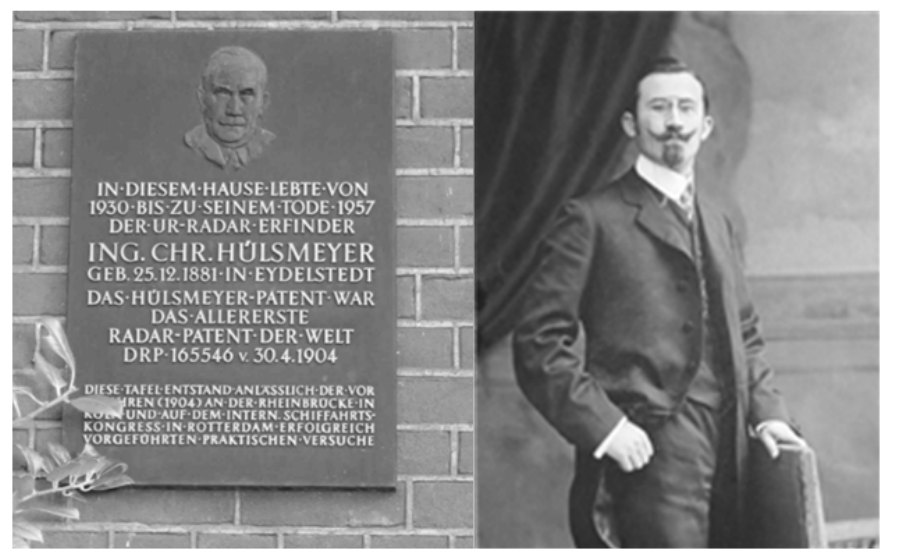

Figure 1. (a) the plate on the Hülsmeyer house in Eydelstedt. (b) The young Hülsmeyer (ca. 1904, at the time of the first patent on radar).

Thanks to these events, today, everybody agrees on the fact that the paternity of radar belongs to Christian Hülsmeyer, who not only demonstrated the effectiveness of his invention by field tests in Cologne in May 1904 and in Rotterdam on June $9^{\text {th }}, 1904$ (the original Hülsmeyer's patent DE 165546 is dated April 30 ${ }^{\text {th }}$, see Figure 3, but also improved the invention, patent DE 169154, see Figure 4, where the critical point of range measurement is further developed (the azimuth measurement having been developed in the original patent, see Figure 5).

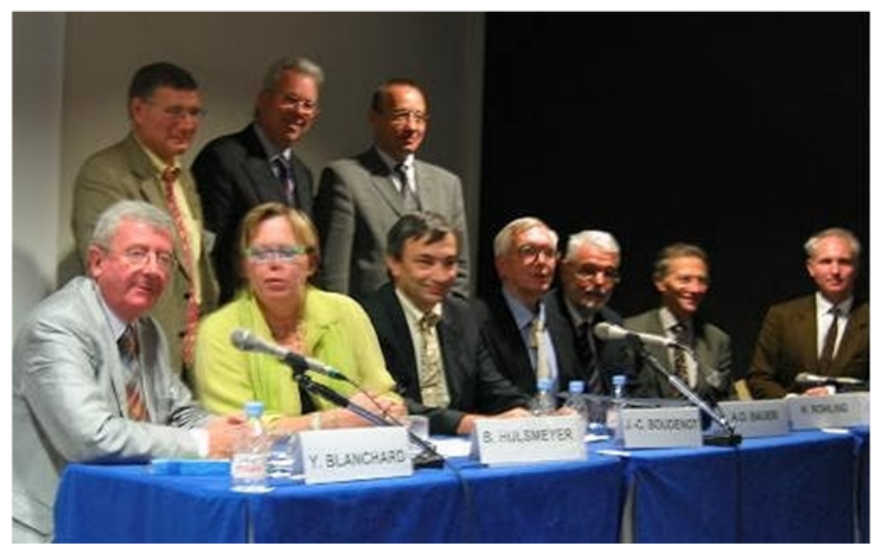

Figure 2. The DGON meeting on the first patent on radar, 2004 - seated, from left: Yves Blanchard (session chairman), Bettina Hülsmeyer (grand-daughter of the inventor), Jean-Claude Boudenot (Thales Research \& Technology), Arthur Bauer (Center for German Communication and related Technology, Diemen, NL), Hermann Röhling, Technische Universität - Hamburg), JeanMarie Colin (Thales Airborne Systems), Pierre-Eric Mounier-Kuhn (Centre Roland Mousnier CNRS / Paris IV-Sorbonne).

In spite of all his efforts, including the association with Heinrich Mannheim, a trader in Cologne who contributed with 2000 DM, as well as the extension of his patents to many nations, including Italy (see Fig. 1.3 of [5]), Hülsmeyer could not sell his invention. Shortly: the environment was not ready to accept the new invention, yet.

Hence, quickly (and successfully) Hülsmeyer moved to other business and the Telemobiloskop was ignored for thirty years. Therefore, in [5] Hülsmeyer is called the unlucky inventor, as opposed to the seven years older lucky inventor Guglielmo Marconi whose contribution to radar, unlike some writings and opinions, was found in [5] to be nearly zero. 
Fig. $r$.
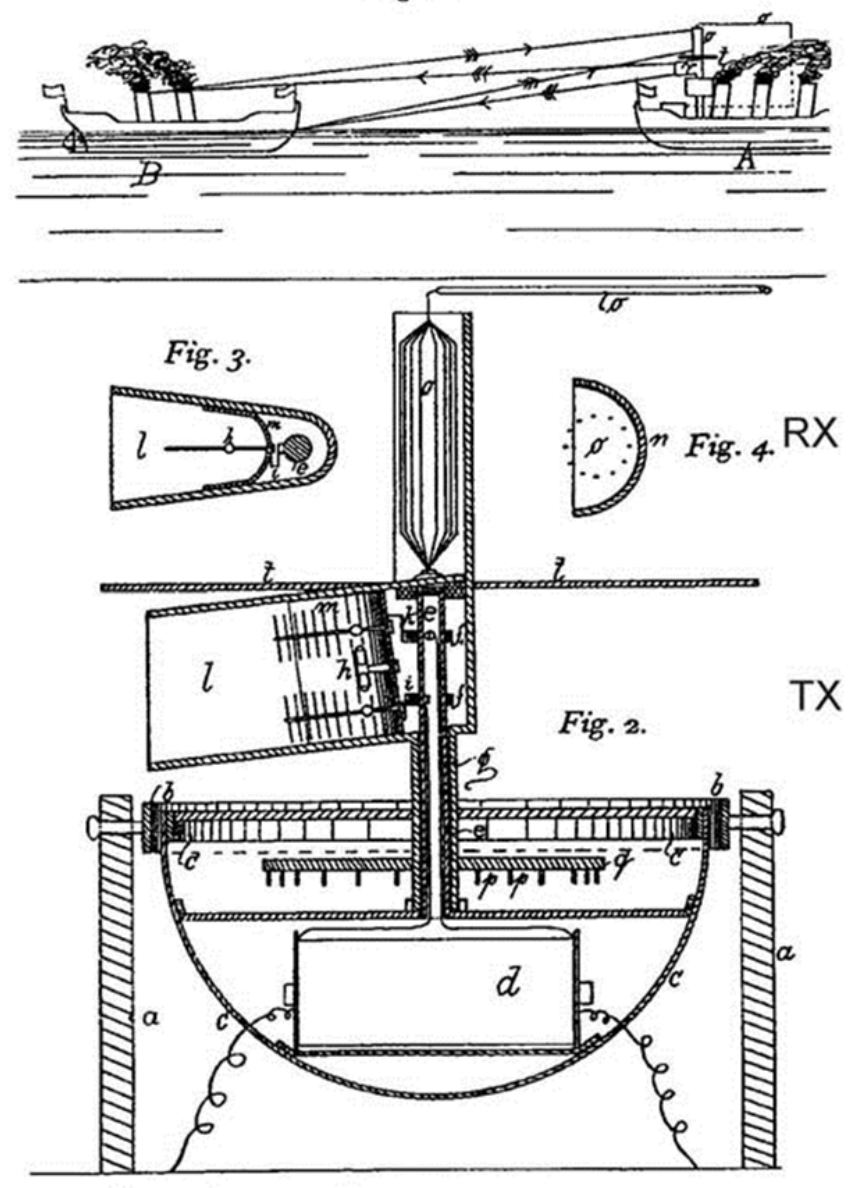

Figure 3. The first page of the original patent DE 165546, Hülsmeyer, 1904.

\section{THE LITERATURE - NEED FOR UPDATING AND COMPLETION}

In addition to the proceedings of conferences, symposia, and meetings, and the ensuing books/booklets originating from them (e.g. [1], [2], [3]), there are numerous publications on radar history; for instance, the References of the most recent book, i.e. [5], include as much as three hundred items with over forty books, mostly in English.

Therefore, a question arises, i.e. why to present a special session "only" ten years after the centenary's events in 2004. Of course our aim is not an analysis of ten-year advancements: history can be analyzed only after the time needed for reflection and for avoiding some potential biases due to any possible running competition between the involved industrial and scientific entities.

However, even neglecting a limited and needed attention to be paid to the latest years, there is still much to be presented on historical radar developments at a conference, because:

a) The younger radar engineers/scientists did not participate to the historical events that happened ten years ago, or more.

b) In the presentations/papers of 1985, 2004 and other, the Italian contribution (Ugo Tiberio, the Gufo (Owl), the first formulation of the radar equation, ...) is virtually absent.
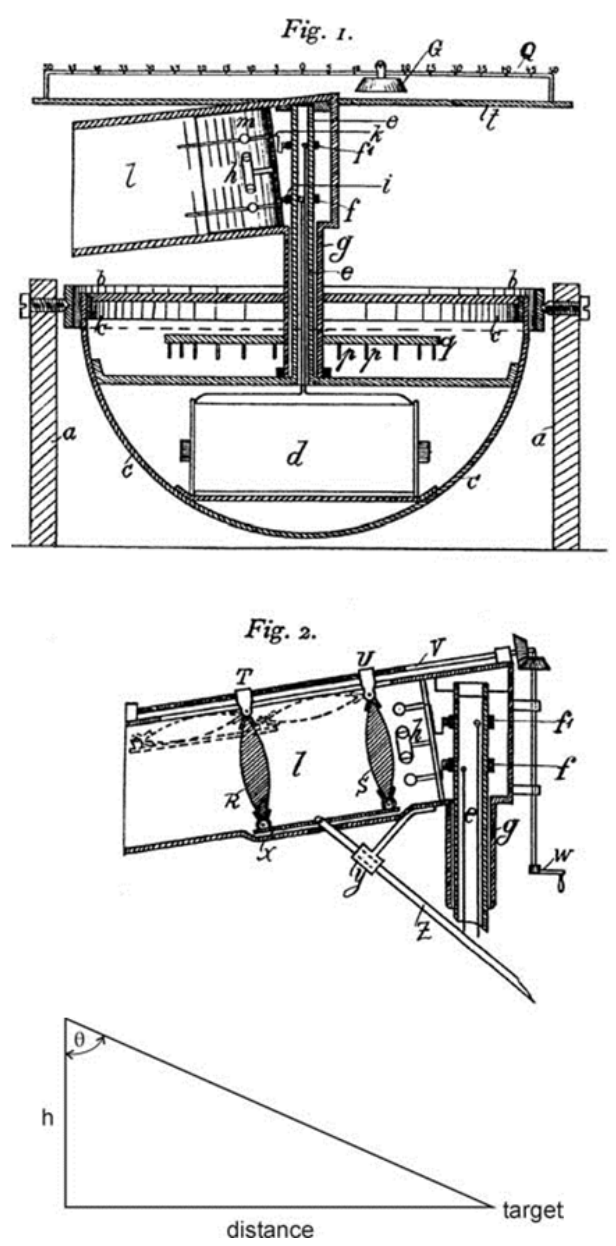

Figure 4. Range measurement in the Hülsmeyer's patent DE 169154, substituting DE165546.

Today there is a renewed interest in Italy on the radar history, and many radar experts think it is time to review this situation. Moreover the role of Guglielmo Marconi in the radar development has to be clarified, including "the IRE speech" and the "experiments" at Acquafredda, Via del Mare e Torre Chiaruccia that many authors continue to recall without using the needed criticism.

c) In addition, in most books and conferences the contributions to radar by Germany, Russia, France (and also The Netherlands and other nations) before 1946 are poorly and scarcely treated in comparison with the, although very significant, British and American ones. The latter are found in a very rich Anglo-American literature, mostly related to the extraordinary developments during W.W. II, such as [11] to mention only one. Anyway some books discussing most of the "not-Anglo-American" contributions, being not written in English [5], [6], [7] are not as widely known as they deserve. Hence, the name "Europe", in the sense of continental Europe, has been inserted in the title of the Special Session.

d) There is a continuing interest, shown by meetings and publications, on the historical development of radar techniques and technologies, for example: MTI, Airborne Radar, Transmitters (with the wartime Tracking Radar (starting with the Würzburg [7], [10]), Bistatic and Passive 
Radar (starting from Klein Heidelberg, [8] and its References), Magnetron and its ancestors ([9] and its References), Pulse Compression (and related technologies : dispersive delay circuits, SAW compressor/expanders....), Phased Array Radar, Adaptive Arrays (starting with the early Side Lobe Canceller, the MSLC...), etc.

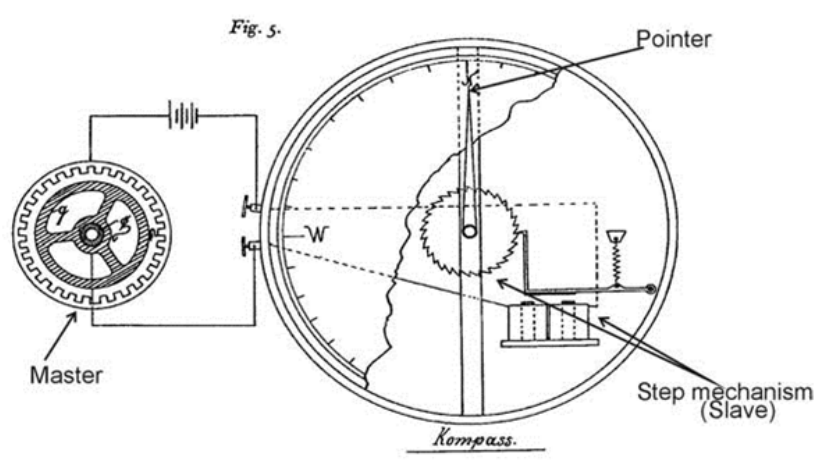

Figure 5. Azimuth encoding in the Hülsmeyer patent DE 165546.

e) Many system-level applications of radar technologies deserve historical interest. They include: air defense, fleet defense, air traffic control, meteorology, navigation and vessel traffic management, automotive applications, and others.

f) It is worth to commemorate some of the European researchers and scientists that contributed significantly to radar (one name for all: the recently (2010) deceased Y.D. Shirman).

g) Important lessons are (to be) learnt from the history of science and technology.

\section{LESSONS LEARNT AND TO LEARN}

The history of technology is a useful complement for the education of engineers, teaching some relevant items which today may be overlooked. Among them:

a) New ideas are applied only when the society is ready to accept them. Hülsmeyer's telemobiloskop was ignored for thirty years due to the lack of an urgent and precise need for it. Around 1932-34 this need arose mainly due to (i) the political international instability following W.W.I, (ii) the rearmament of Germany in the thirties and (iii) the increased capacity of new aircraft, capable of bombing with mass raids a foreign territory. The resulting research and development of air defense, and hence of means for the warning of enemy aircraft, led to design - and production in quantities of hundreds or thousands - some equipment (with a strange appearance according to today's standards), the aerophones, as shown in Figure 6. The Tucker system, based on a large "sound mirror" in Dengie, was visited in summer 1934 by a delegation of the Air Ministry - including R. Watson-Watt - with the aim to select the optimal air defense sensors. Despite of the obvious limitations (environmental noise, low speed of propagation) of the usage of sound waves, the need was so strong as to bring to an immediate decision (January, 1935) to plan a complete early warning system based on Tucker's sound mirrors, with more than 500 persons working on it in June. However, the success of the Watson-Watts trials of the more suited radar technology stopped the sound mirrors activity in September, 1935. As it is well known, e.g. [4], [11], in 1934-35 the society was so ready to accept the "new idea" of radar to lead to a working prototype in a few months' time and to a complete system, the Chain Home (operational in the UK in 1939), in very few years.
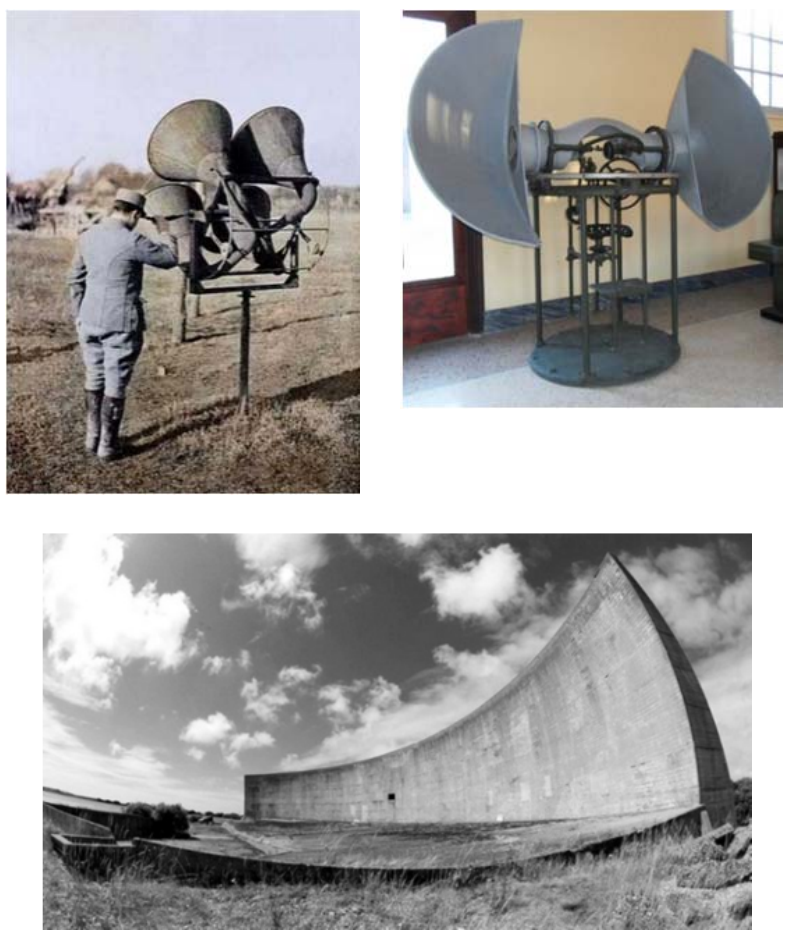

Figure 6. Top: Some aerophones from France and Italy, Bottom: Sound mirror - 60 meters long - in Dengie, Great Britain. In the area of concrete in front of the wall the researcher William Sansome Tucker installed 20 microphones for a better search for the direction of arrival of the aircraft.

b) Most technological developments arrive without prior notice; in other words, a retrospective exam of technical and scientific forecasts show that they were mostly false, anyway meaningless or useless. The fact that aerophones and sound mirrors were quickly surpassed by the unnoticed radar, developed in parallel and under strict secrecy by many nations, is just one example. May be a more recent, stronger example is that of the advent of digital signal processing in radar, see for instance [12]. M.I. Skolnik once called this a "notannounced revolution" noting that radar engineers were too busy to study and apply digital signal processing to find any time to advertise it. However, on the other side of the medal, there are some announced "revolutionary" developments which did not arrive in a reasonable time frame, - yet.

A well-known related example is quantum cryptography (more precisely, quantum key distribution), announced in the early 1980's (Bennet and Brassard, 1984) by research and, later, important industrial bodies as the "Holy Grail" of security, (an overview is in [13]). But unfortunately it is not available in any practical product on the market today, i.e. 
thirty years later (not to mention the more and more difficult quantum computation).

c) Need for criticism (not only in the radar field). Teaching students and engineers to be critical is most important today, especially because, in addition to the old and new preconceived ideas, there is much (maybe, too much) and (maybe too) confusing information readily available on the Web.

\section{The Special SESSION's SELECTED topics}

Of course, in four papers it is only possible to treat a small part of the topics listed in Section II. Hence, a choice has been made based upon some subjective priorities as well as on the availability of the distinguished authors who kindly accepted the invitation to contribute to this Session.

The resulting outline includes the following:

- The paper "From Huelsmeyer's Telemobiloskop to the Digital Radar" by Hermann Rohling, in which the radar development is described starting from the pioneering work by James C. Maxwell and Heinrich Hertz on "electric waves" and by Alexander S. Popov and Guglielmo Marconi on wireless (later, called radio) communications. Special attention is paid to the advent of digital radar technologies and to the civil applications: Air Traffic Control, Vessel Traffic System, Automotive radar.

- The paper by Yves Blanchard on the Atlantic Wall, built by the German forces along the occupied coasts of Western Europa to protect them from allied landing attempts : not only a defence line with clusters of concrete bunkers, artillery, minefields and so on, but also a radar surveillance and alert chain, facing the British Chain Home during W.W. II. The differences with respect to the Chain Home organization are highlighted, as well its remains 70 years later, especially in France. The paper also describes the discovery of the Atlantic Wall chain by the Allies, and their counter-measures, which made it quite inefficient during the crucial days of June 1944 in Normandy.

- The paper on the Ukrainian contribution to radar by Felix Yanowsky, starting from the early development of needed high-power tubes (1920's and 1930's) describes the main steps for Ukrainian-developed radar technology including Multiple MTI, Pulse compression, Statistical Radar, Adaptive Signal Processing, ECCM, Multistatic passive radar, Meteorological radar, and others. It concludes with the very relevant radar developments in the Independent Ukraine.

- The paper by Gaspare Galati on the Italian contribution to radar, whose publication is needed as in nearly all publications in English, this contribution is practically absent. This paper contains three main elements, i.e. the Gufo (owl), the first Italian operational radar - designed by Ugo Tiberio and developed by the SAFAR company, the first formulation of the radar equation in the literature Ugo Tiberio), and some results of historical research demystifying Marconi's contribution to radar.

\section{FOR FURTHER READING}

We do hope this Special Session on 110 years of radar developments in Europe after Hulsmeyer's Telemobiloskop will enhance interest on the fascinating, and often overlooked, history of radar, especially of European radar, here treated in a necessarily limited way. The interested persons may find additional information not only in the few References mentioned below and in their numerous References, but also in many web sites, including the following ones:

www.radarmuseum.co.uk

http://www.rememuseum.org.uk/corphistory.aspx http://www.antiaircraft.co.uk/index.html

http://www.nsarc.ca/hf/german radar.pdf

http://aobauer.home.xs4all.nl/

http://www.radarworld.org/index.html

http://spitfiresite.com/2010/04/deflating-british-radar-myths-of-worldwar-ii.html/6

http://www.meteor.iastate.edu/ jdduda/portfolio/HistoryPPT.pdf www.cdvandt.org

http://www.cdvandt.org/German\%20airborne\%20radar\%20def.pdf

http://www.encyclopedia.com/doc/10129-

radar.htmlhttp://www.radarpages.co.uk/mob/ch/chainhome.htm http://www.clepair.net/radar-web.htm

http://web.archive.org/web/20071005024529/http://www.radarfrance.net/

http://www.ieeeghn.org/wiki/images/0/0e/Tracking the History of Ra dar.pdf

http://www.radarworld.org/america.html

\section{REFERENCES}

[1] Hermann Rohling \& al. "100 years of Radar - Contributions from various countries describing the individual Radar development processes", DGON (Deutsche Gesellschaft für Ortung und Navigation e.V.) Special Issue, 2005.

[2] Piet Van Genderen \& al. "Radar Development in the Netherlands", Thales Nederland ed., Hengelo, 2004.

[3] Proceedings of the session "The history of radar development to 1945", International Radar Conference, London, October 1985 (with 38 papers presented by various nations).

[4] Sean S. Swords "Technical History of the beginnings of RADAR", Peter Peregrinus/IEE (Institute of Electric Engineers), History of Technology Series 8, London, 1986.

[5] Gaspare Galati - "Cent'anni di radar - Ricerca, Sviluppi, Persone, Eventi" [One Hundred Years of Radar - Research, Developments, Persons, Events], ARACNE Editrice, Roma, 2012 (in Italian).

[6] Yves Blanchard "Le Radar 1904-2004, histoire d'un siècle d'innovations techniques et opérationnelle" [The Radar 1904-2004: History of One Century of Technical and Operational Innovations, Ellipses ed., Paris, 2004 (in French).

[7] Arthur O. Bauer "Deckname Würzburg- Ein Betrag zu Erhellung der Geschichte des geheimnisunwitterten deutscher Radargeräts 19371945", Verlag Historischer. Technikliteratur, Herten, Germany, 1992.

[8] Hugh Griffiths "The Klein Heidelberg”, IEEE Trans. on Aerospace and Electronic System, Vol AES 46 No. 4, Oct 2010.

[9] Yves Blanchard, Gaspare Galati, and Piet van Genderen "The Cavity Magnetron: Not Just a British Invention", IEEE Antennas and Propagation Magazine, Vol. 55, No. 5, October 2013.

[10] Hugh Griffiths, "The Wúrzburg radar equipment from the Bruneval raid”, IEEE AES Magazine, Vol. 29, nr 4, pp 14-19, April 2014.

[11] Henry E. Guerlac (Editor) "Radar in World War II" (The History of Modern Physics 1800-1950, Two volumes: Sect. A-C, and Sect. D-E with Appendices), American Institute of Physics, 1987, ISBN 9780883184868 .

[12] Hermann Rohling “From Huelsmeyer's Telemobiloskop to the Digital Radar", this Issue.

[13] http://www1.cse.wustl.edu/ jain/cse571-07/ftp/quantum/index.html 